\title{
INNOVATION ACTIVITY AND FIRM HETEROGENEITY: EMPIRICAL EVIDENCE FROM WEST GERMANY
}

\author{
FRANÇOIS LAISNEY, ${ }^{1}$ MICHAEL LECHNER ${ }^{2}$ AND WINFRIED \\ POHLMEIER ${ }^{3}$
}

This paper investigates the robustness of cross-section results on innovative behaviour of firms. It discusses specifications resulting from various assumptions on market structure and strategic behaviour. A number of cross-section and pooled probit results rely on restrictions which are rejected. The specification with correlated random effects is rejected and yields poor results, but the absence of correlation between random effects and regressors is also rejected.

\section{INTRODUCTION}

The primary goal of this paper is to investigate the robustness of cross-section results on innovative behaviour to the types of treatment of unobserved heterogeneity made feasible by panel data. The lack of robustness of cross-section estimates of production functions is documented, for instance, by Mairesse and Griliches (1990), who also draw attention to the difficulty of distinguishing between the effects of neglected heterogeneity and those of further misspecifications. Our tool of investigation here is Chamberlain's approach to panel probit estimation coupled with intensive testing in both stages of the estimation procedure, with joint tests across periods for the first stage. This aspect of the paper is novel and relies on Lechner (1992).

This paper is organized as follows: in Section 2 we justify the use of the same first-order conditions in an intertemporal context as those used previously in a purely static context and draw attention to the complexity of the stochastic structure implied by this model. We discuss alternative specifications which result from various assumptions being made about the market structure and strategic market behaviour. This section ends with a presentation of the equation to be estimated. Section 3 describes the data, and Section 4 presents estimation and test results for various specifications and estimation methods which differ only through the stochastic assumptions and, especially, through the extent to which restrictions are placed on the unobserved heterogeneity. We find that the cross-section and the pooled probit results rely on restrictions which are rejected

\footnotetext{
' BETA, Université Louis Pasteur, Strasbourg, France and ZEW.

2 Institut für Volkswirtschaftslehre und Statistik, Universität Mannheim and ZEW.

${ }^{3}$ Lehrstuhl für Volkswirtschaftslehre, insbesondere Ökonometrie, Universität Mannheim and ZEW.
} 
by the data. The specification with correlated random effects is rejected and yields poor results, yet the absence of correlation between random effects and regressors is also rejected. The phenomena behind these findings deserve further investigation.

\section{MODEL SPECIFICATION AND STOCHASTIC STRUCTURE}

In this section we show how behavioural assumptions about the reaction of firms with respect to their competitors, beyond providing certain parametric restrictions on the behavioural equations under investigation, also place strong restrictions on the nature of the underlying stochastic process. In order to avoid the complexities inherent in models of product innovation, which have to take account of different markets and possible discontinuities, we restrict our attention to a simple dynamic model of a firm's process innovating behaviour in a homogeneous product market.

The model we use as a guide-line for our econometric specifications is based on the assumption of a two-stage decision process. At any instant of time the firm has chosen its cost minimal combination of factor inputs for a given level of output and technological know-how (i.e. realized process innovations). The long run decision process is characterized by the choice of the profit maximizing levels of output and R\&D investments over time. Let production costs for the $i$ th oligopolistic competitor at time $t$ be represented by the following constant returns to scale cost function:

$$
C\left(T_{t}, Z_{t}, w_{t}, q_{t}\right)=c\left(T_{t}, Z_{t}, w_{t}\right) \cdot q_{t}
$$

with

$$
\frac{\partial C}{\partial T}<0 \quad \frac{\partial^{2} C}{\partial T^{2}}>0
$$

where $q$ is output and $w$ is a vector of input prices. The set of variables $Z$ accounts for observed interfirm differences in production costs. $T$ captures the firm's innovative success in the sense of successfully installed technological know-how. This has to be distinguished from innovative input (usually described by $R \& D$ expenditures) which does not necessarily translate into innovative output on a one to one basis, as many studies implicitly assume (see Kamien and Schwartz, 1969; Link, 1980, for criticism and discussion; and also Hall and Hayashi, 1989). Our approach adopts a distinction made by Griliches (1979), who proposes to treat $R \& D$ expenditures as a flow variable which reflects the innovative input of a firm. In order to capture the idea of this distinction, let successfully installed process innovations be given by the following flow equation:

$$
T_{t}=(1-\delta) T_{t-1}+F\left(R_{t}, Y_{t}\right) \quad \forall t
$$

where $R$ denotes $\mathrm{R} \& \mathrm{D}$ expenditures, and $F(\cdot)$ represents the innovation production function with $Y$ as a set of variables that have an effect on this transformation process (e.g. accessibility to $R \& D$ resources, economies of scope 
in $R \& D$ due to multiproduct production). The parameter $\delta$ is the depreciation rate. Total industrial output $Q$ is produced by $n$ monopolistic competitors and a competitive fringe $x$. Given equation (2.2), an oligopolistic competitor maximizes the present value of its profit stream over an infinite horizon under perfect foresight: ${ }^{4}$

$$
\max _{q_{i}, R_{i}} \pi_{i t}=\sum_{\tau=t}^{\tau=\infty}\left\{\left[p\left(Q_{\tau}\right)-c\left(T_{i \tau}, Z_{i \tau}, w_{i \tau}\right)\right] q_{i \tau}-R_{i \tau}\right\}(1+r)^{t-\tau}
$$

where

$$
\begin{aligned}
q_{i} & =\left(q_{i t}, q_{i, t+1}, \ldots\right) \\
R_{i} & =\left(R_{i t}, R_{i, t+1}, \ldots\right) \\
Q_{t} & =\sum_{j=1}^{n} q_{j t}+x_{t} \\
p_{t} & =p\left(Q_{t}, V_{t}\right)
\end{aligned}
$$

where $p(\cdot)$ defines the inverse of the demand function with $V$ a vector of shift factors. For simplicity the interest rate $r$ is assumed constant over time. Even for the static case there generally exists no closed form solution for the maximization problem presented above due to the complex interactions between competitors. Thus econometric approaches usually estimate a transformation of the first-order conditions. The first-order condition with respect to $q_{i t}$ for an interior solution of problem (2.3) produces the well known equality between marginal revenue and marginal costs:

$$
p_{t}\left(1-m_{i t}\right)-c\left(T_{i t}, Z_{i t}, w_{i t}\right)=0
$$

where

$$
m_{i t}=-\frac{q_{i t}}{p_{t}} \frac{\partial p_{t}}{\partial Q_{t}} \frac{\partial Q_{t}}{\partial q_{i t}}
$$

denotes minus the elasticity of market price to output of the $i$ th firm and corresponds to the mark-up of prices over marginal costs.

An econometric specification for process innovations that is solely based on equation (2.4) has two interesting properties. Firstly, although the model is dynamic in essence, a subset of the parameters can be estimated using only the cross-sectional information, since all the dynamic features of the model are incorporated in the f.o.c. for $R$. Hence, interesting information on the transformation process from innovative input to innovative success is thus neglected. For the kind of data incorporated in the Ifo business survey, which only collects binary information on innovative success, this is clearly an advantage. Secondly, if the major interest lies in the relationship between innovative success and market structure, the first-order condition with respect to output implicitly captures all available information on the firms' market behaviour via $m_{i}$.

\footnotetext{
4 The extension to uncertainty concerning factor prices and interest rates is straightforward and leads to a stochastic Euler equation.
} 
Nevertheless this approach has the drawback that it is generally impossible to check the second-order condition in this framework, i.e. without further specification of the market structure. For the Cournot assumption, for example, we can easily check an implication of the second-order condition using only the submatrix corresponding to $q_{i t}$ : in this case the corresponding diagonal elements of the Hessian have a simple form which will be given below after the introduction of the necessary notation.

For the econometric specification we assume a standard isoelastic demand function of the form:

$$
Q_{t}=\tilde{p}\left(V_{t}\right) p_{t}^{-\epsilon}
$$

and a firm specific cost function given by:

$$
C_{i t}\left(T_{i t}, Z_{i t}, w_{i t}, q_{i t}\right)=\left(1+v_{i}\right) \tilde{c}\left(Z_{i t}, w_{i t}\right) T_{i t}^{-\beta} q_{i t} \quad \beta>0
$$

where $v$ represents a normally distributed random variable with an expectation zero which captures firm specific differences in production costs that are known to the firm but unobservable to the econometrician. Given the parametric specifications on the demand function and the cost function, and assuming perfect factor markets (i.e. identical factor prices for all competitors), a simple log-linear relationship between process innovation and market structure variables can be derived:

$$
\ln T_{i t}=c_{t}+(1 / \beta) v_{i}+\frac{1}{\epsilon \beta} \ln Q_{t}+\frac{1}{\beta} m_{i t}+g\left(V_{t}, Z_{i t}\right)
$$

where we have made use of the approximation $\ln (1+x) \approx x$.

The parameter $c_{t}$ represents a time varying intercept. Given information on Lerner's index of monopoly power, equation (2.7) has the form of a random effects specification with a time dependent intercept term which could be estimated using fairly standard econometric methods on panel data. It will soon become clear that the specific assumptions made about the reaction pattern of competitors will have serious implications with respect to the stochastic nature of the composite error term.

\subsection{Models Without a Competitive Fringe}

Without discussing the problems of the theoretical consistency of oligopolistic models with conjectural variations (see, e.g. Shapiro, 1989) it is obvious by the definition of the mark-up factor that additional identifying assumptions have to be made in order to estimate $m_{i t}$. The following argument holds whether we treat the reaction of total market output along the lines of the 'new empirical industrial organization' (NEIO) in which a single parameter reflects the underlying assumptions on market behaviour (e.g. Porter, 1983; Lee and Porter, 1984) or in the language of the 'conjectural variations' (CV) literature where a firm's price cost mark-up is modelled as a function of its expectations about the reaction of other firms to an increase in quantity. In the literature on conjectural variations it is common to assume that a percentage change in the output of any firm $j$ to a $1 \%$ 
move of firm $i$ does not depend upon the identity of firm $j$ :

$$
\eta_{i t} \equiv \eta_{i j t}=: \frac{\partial q_{j t}}{\partial q_{i t}} \frac{q_{i t}}{q_{j t}} \quad i \neq j
$$

This yields a mark-up factor of the form:

$$
m_{i t}=\frac{1}{\epsilon}\left[S_{i t}+\eta_{i t}\left(1-S_{i t}\right)\right]
$$

where $S_{i t}$ denotes the market share $S_{i t}=: q_{i t} / Q_{t}$.

When panel data is available, it makes sense to decompose the elasticity of conjectural variation into a constant term, a fixed period-specific effect and a random individual effect:

$$
\eta_{i t}=\eta+\mu_{t}+v_{i} \quad E v_{i}=0, \quad V v_{i}=\sigma_{v}^{2} .
$$

Substitution of (2.8) into (2.6) leads to an equation that relates successful process innovations to market structure variables:

$$
\ln T_{i t}=\gamma_{t}+\frac{1}{\epsilon \beta} \ln Q_{t}+\alpha_{t} S_{i t}+g\left(V_{t}, Z_{i t}\right)+\xi_{i t}
$$

where $\gamma_{t}=c_{t}+\left(\eta+\mu_{t}\right) / \beta \epsilon$ is a time variable intercept and $\alpha_{t}:=\left(1-\eta-\mu_{t}\right) / \beta \epsilon$ is a time-varying slope parameter. The composite error term is of the form:

$$
\xi_{i t}:=(1 / \beta) v_{i}+v_{i}\left(1-S_{i t}\right) / \beta \epsilon .
$$

Since the error term $\xi_{i t}$ depends on both $v_{i}$ and $S_{i t}$, both heteroscedasticity and autocorrelation will exist and be of a known form. Here we have introduced stochastic aspects through the mark-up factor only, but other sources will interact with this, preventing the simple correction for heteroscedasticity consisting of dividing through by $1-S_{i t}$. This simple example shows nicely that theoretical assumptions made about a firms' market strategies will interact with those assumptions made about the composite error term. Therefore, panel data approaches which account purely for some kind of heterogeneity are not directly suited to the estimation of this model. Approaches in the spirit of the specification outlined above call for panel econometric methods that are more general with respect to the underlying assumptions about the error term such as the correlated random effects approach with time varying parameters. Estimates of $\alpha_{t}$ give insight on whether the market moved towards more competitive behaviour or not. Moreover, a simple test of the hypothesis $\alpha_{t}=\alpha$ gives insight into the stability of market behaviour over time.

A special case of (2.7) that deserves more attention is Cournot behaviour (i.e. $\left.\eta_{i j t}=0\right)$. Under the Cournot assumption, equation (2.10) reduces to:

$$
\ln T_{i t}=c_{t}+\frac{1}{\epsilon \beta} \ln Q_{t}+\frac{1}{\epsilon \beta} S_{i t}+g\left(V_{t}, Z_{i t}\right)+(1 / \beta) v_{i}
$$


This restricts the coefficients of $\ln Q_{t}$ and $S_{i t}$ to equality if the approximation made for equation (2.6) holds. Furthermore, the stochastic structure is drastically simplified since the error term is no longer affected by heteroscedasticity through the market share variable and the model reduces to a standard random effect specification. ${ }^{5}$ Similar arguments hold for the collusion case $\left(\eta_{i j t}=1\right)$, which puts a zero restriction on the coefficient of $S_{i t}$.

\subsection{Models with a Competitive Fringe}

In the group of models described above, all firms are treated as competitors with some degree of monopoly power. A simple generalization leads to competitive fringe models which assume that some share of total market output is produced by a number of small, price taking firms. Thus, the profit margin also depends on the relative market power of the oligopolistic competitors to the competitive fringe. This generalization leads to a price cost mark-up of the form:

$$
m_{i t}=\frac{S_{i t}+\eta_{i t}\left(K_{t}-S_{i t}\right)}{\epsilon+\kappa\left(1-K_{t}\right)}
$$

where

$$
\kappa \equiv \frac{\partial p_{t}}{\partial x_{t}} \frac{x_{t}}{p_{t}} \quad K_{t} \equiv \frac{Q_{t}-x_{t}}{Q_{t}} .
$$

The existence of a competitive fringe complicates the econometric specification substantially since $m_{i t}$ becomes a highly non-linear function in $S_{i t}$ and the $n$-firm concentration ratio $K_{t}$. A simple, but not very elegant, solution to this problem is to estimate (2.6) by using a linearized version of (2.13).

In the following empirical application, our starting point for the specification is a competitive fringe model. For all firms in the sample we assume Cournot behaviour. Linearization of the mark-up term around $k(1-K)$ leads to: ${ }^{6}$

$$
m_{i t} \approx \frac{1}{\epsilon} S_{i t}-\frac{K}{\epsilon^{2}}\left(1-K_{t}\right) S_{i t}
$$

Inserting (2.14) in equation (2.6) leads to the random effects specification:

$$
\ln T_{i t}=c_{t}+\frac{1}{\epsilon \beta} \ln Q_{t}+\frac{1}{\epsilon \beta} S_{i t}-\frac{K}{\beta \epsilon^{2}} S_{i t}\left(1-K_{1}\right)+g\left(V_{t}, Z_{i t}\right)+(1 / \beta) v_{i}+u_{i t}
$$

where $u_{i t}$ represents a conventional error term uncorrelated across firms but possibly correlated over time. The function $g(\cdot)$ captures observable heterogeneity concerning the impact of exogenous variables $V$ on total demand and of exogenous variables $Z$ on production costs. We will assume that the function $g$ is linear and test this functional form.

\footnotetext{
5 The following implication of the second-order condition can then easily be checked: $\pi_{q q}=$ $(1-m) \partial p / \partial q-[1 /(Q(1-S))] p / q<0$.

6 This step uses the approximation formula $1 /(\alpha+x) \approx 1 / \alpha-x / \alpha^{2}$ for small $x$, see Bronstein and Semendjajew (1982, p. 101) for the evaluation of the approximation error.
} 
Two major problems arise concerning the interpretation of the estimated coefficients. Firstly, although the signs on the coefficients are in accordance with a variety of empirical specifications which are more or less directly derived from economic theory, equation (2.13) above does not represent a causal relationship, but only reflects a relationship derived from optimal firm behaviour similar to Euler equation approaches. ${ }^{7}$ The simultaneity problem can be treated by instrumenting the market share variable and the concentration ratio. Secondly, other, similar, models can be derived, and some of these produce different signs for the coefficients on the variables listed above. Thus more information, such as parameter estimates of the demand function, is needed in order to identify the parameters separately (see Breshnahan, 1989, for a more elaborate treatment of the argument).

\section{DATA}

We conduct our analysis on a five-wave, balanced panel of 1325 West German firms from the Ifo business survey 'Konjunkturtest' for 1984-88, using the specific questions asked yearly on innovation behaviour. The indicator for process innovation we use, denoted $I C$, corresponds to the positive assertion 'for product $X$ we have realised process (product) innovations in the year $Y^{\prime}$ (see Oppenländer and Poser, 1989, p. 269).

From Table 1, which gives summary statistics about variables used in the model, one can see that the proportion of firms recording process innovation varied between $49.7 \%$ in 1985 and $55.7 \%$ in 1986 .

The 'firms' considered in the panel are actually 'one-product-firms' (OPFs), which means that each plant produces a single good at the two-digit level in the nomenclature of the Federal Statistical Office (Statistiches Bundesamt). We have retained only those OPEs that are present in all waves and which have no values missing on any of the recorded variables. The number of such units belonging to the same company in the sample ranges from one to seven. For each OPF we know both the employment at the product level EMPLP and at the company level EMPLU. ${ }^{8}$ Data at the two-digit industry level obtained from the German Statistical Year-books 1986-90 and the German Monopolkommission (1985-86, $1987-88$ and 1989-90) give us the industry employment $E B$, the industry value added $Q B$ (expressed in millions of current $\mathrm{DM}^{9}$ ) and the share of the six largest firms in total industry sales $U 6$. From these raw data we construct several new

\footnotetext{
7 The reader may find the indirectness of this approach disturbing, and prefer the estimation of a closed-form solution for process innovation activity. However, on the one hand, such closed form solution is not generally available in oligopoly theory and, on the other hand, the indirect approach is often used in econometrics. For instance, Hotz et al. (1988) use the first-order conditions on consumption in order to identify parameters relating to labour supply.

8 The large increase in the average number of company employees between 1986 and 1987 is mainly due to an outlier.

9 The inflation rate over the period considered was so small that no deflation was necessary. Since $Q B$ is the only nominal variable used, and since it appears in log-linear form in the model, time dummies would take care of inflation effects anyway.
} 
TABle 1. Descriptive Statistics (1325 Observations)

\begin{tabular}{|c|c|c|c|c|c|c|}
\hline \multirow[t]{2}{*}{ Variable } & \multirow[t]{2}{*}{ Description } & \multicolumn{5}{|c|}{ Mean } \\
\hline & & 1984 & 1985 & 1986 & 1987 & 1988 \\
\hline IC & Process innovation realized (dummy) & 0.5140 & 0.4966 & 0.5570 & 0.5125 & 0.5487 \\
\hline$E M P L P$ & OPF employment (number of employees) & 525.29 & 528.56 & 597.49 & 598.56 & 609.09 \\
\hline$E M P L U$ & Firm employment (number of employees) & 3322.3 & 3583.5 & 3740.6 & 4316.9 & 4263.5 \\
\hline$E B$ & Industry employment $^{1}$ & 445419 & 456455 & 472715 & 474534 & 474762 \\
\hline$S P$ & Relative size (EMPLP/EB) & 0.0024 & 0.0024 & 0.0028 & 0.0027 & 0.0028 \\
\hline DTPP & Strong positive total demand expectations & 0.0453 & 0.0408 & 0.0332 & 0.0294 & 0.0445 \\
\hline DTP & Merely positive total demand expectations & 0.4106 & 0.4309 & 0.4219 & 0.3849 & 0.4958 \\
\hline DTMMM & Negative total demand expectations & 0.1404 & 0.1185 & 0.1313 & 0.1577 & 0.1011 \\
\hline SU84 & Share of OPFs in firm employment (EMPLP/EMPLU) & 0.6060 & 0.5980 & 0.6559 & 0.6598 & 0.6672 \\
\hline SU2 & OPF small versus firm (dummy $S U<0.2$ ) & 0.1525 & 0.1502 & 0.1396 & 0.1479 & 0.1457 \\
\hline SU8 & OPF large versus firm (dummy $S U>0.8$ ) & 0.3442 & 0.3260 & 0.4596 & 0.4702 & 0.4815 \\
\hline$Q B$ & Industry value added & 37507 & 40222 & 42383 & 43853 & 46798 \\
\hline U6 & Share of six largest firms in industry sales & 0.2183 & 0.2195 & 0.2089 & 0.2097 & 0.2120 \\
\hline$I M Q$ & Import share in industry domestic supply & 0.6370 & 0.7015 & 0.6749 & 0.6483 & 0.6723 \\
\hline$W A G E$ & Hourly wage rate in industry (current DM) & 14.83 & 15.45 & 16.02 & 16.70 & 17.44 \\
\hline$G$ & Sector raw materials (dummy) & & & 0.1057 & & \\
\hline$I$ & Sector investment goods (dummy) & & & 0.4845 & & \\
\hline$N$ & Sector foods (dummy) & & & 0.0453 & & \\
\hline C & Sector other consumption goods (dummy) & & & 0.3645 & & \\
\hline
\end{tabular}

1 At the two-digit industry level of Statistical Year-books.

2 In millions of current DM. 
variables: $S P=E M P L P / E B$ is our measure of the relative size of the firm; $S U=E M P L P / E M P L U$ should help capture the economies of scale of multiproduct plants in process innovation. We use this information in the form of two dummies: $S U 8=1 \Leftrightarrow S U>0.8$ indicates firms where such economies of scale are almost non-existent, and $S U 2=1 \Leftrightarrow S U<0.2$ indicates firms where they are greatest. Thus we would expect $S U 8=1(S U 2=1)$ to reduce (increase) the probability of process innovation, other things being equal.

Different variables in the data set depict long run demand expectations. We use these variables as indicating perception of relative cost advantages and include them in the variable set $Z$. Alternatively, one could rationalize these as revealing heterogeneity in the demand elasticity $\epsilon$. After scanning a histogram of the five categories of the discrete variable recording total demand expectations we distinguish between strongly positive expectations $(D T P P=1)$, merely positive expectations $(D T P=1)$, and negative expectations $(D T M M M=1)$. The reference category is difficult to interpret since its precise meaning can be either 'no change' or 'no opinion' (see Ronning, 1990). The proportion of OPFs with the best prospects ranges from $2.9 \%$ in 1987 to $4.5 \%$ in 1988 . Some $40 \%$ in each year have merely positive expectations on total demand and only $10 \%$ (1988) to $16 \%$ (1987) have negative expectations on total demand. Other variables considered in the analysis are the import share of the industry, $I M Q$, considered as a candidate for variable set $V$, as proxy for the relative competitiveness of the industry on the world market, and the average hourly wage rate in the industry, $W A G E$, an obvious candidate for variable set $Z$.

Finally, we consider four sectoral dummies $G$ (raw materials), $I$ (investment goods), $N$ (foods), $C$ (other consumption goods), in order to capture further observable heterogeneity.

\section{RESULTS}

\subsection{Heterogeneity Uncorrelated with the Regressors}

4.1.1. Pooled probit and cross-section estimates. If the true latent model is an error components model of the form

$$
y_{i t}^{*}=x_{i t} \beta+v_{i}+u_{i t}
$$

with $v_{i}$ and $u_{i t}$ independent, i.i.d. jointly normal and independent of $x_{i t}$, then the pooled probit estimator is consistent (see Robinson, 1982). Table 2 gives the estimates corresponding to equation (2.15) for two specifications, one with time dummies and one with a constant intercept. We also estimated these specifications without imposing the restriction of equality of the coefficients related to the variables $S P$ and $\ln Q B$. This restriction is consistently rejected (mildly) throughout the whole analysis presented in this paper, yet the unrestricted model also consistently yields a negative coefficient for $S P$, which makes interpretation of the model impossible. Thus we present restricted estimates throughout and only refer to the unrestricted estimates where appropriate. 
TABle 2. Results of Pooled and Cross-section Probit Estimation

\begin{tabular}{|c|c|c|c|c|c|c|c|c|c|c|c|c|c|c|}
\hline \multirow[t]{3}{*}{ Variable } & \multicolumn{14}{|c|}{ Model } \\
\hline & \multicolumn{2}{|c|}{ Pooled probit } & \multicolumn{2}{|c|}{ Pooled probit } & \multicolumn{2}{|c|}{ Probit 1984} & \multicolumn{2}{|c|}{ Probit 1984} & \multicolumn{2}{|c|}{ Probit 1986} & \multicolumn{2}{|c|}{ Probit 1987} & \multicolumn{2}{|c|}{ Probit 1988} \\
\hline & coefficient & $(t)$ & coefficient & $(t)$ & coefficient & $(t)$ & coefficient & $(t)$ & coefficient & $(t)$ & coefficient & $(t)$ & coefficient & $(t)$ \\
\hline Intercept & -1.345 & $(-6.3)$ & & & -1.397 & $(-3.2)$ & -1.209 & $(-2.6)$ & -1.072 & $(-2.2)$ & -1.616 & $(-3.7)$ & -1.680 & $(-3.8)$ \\
\hline Intercept 1984 & & & -1.335 & $(-6.2)$ & & & & & & & & & & \\
\hline Intercept 1985 & & & -1.411 & $(-6.6)$ & & & & & & & & & & \\
\hline Intercept 1986 & & & -1.246 & $(-5.8)$ & & & & & & & & & & \\
\hline Intercept 1987 & & & -1.340 & $(-6.2)$ & & & & & & & & & & \\
\hline Intercept 1988 & & & -1.316 & $(-6.0)$ & & & & & & & & & & \\
\hline$S P+\ln Q B$ & 0.096 & (4.4) & 0.094 & (4.3) & 0.094 & (2.1) & 0.089 & (1.9) & 0.092 & (1.9) & 0.104 & (2.3) & 0.116 & (2.6) \\
\hline \multicolumn{15}{|l|}{ Demand expectation } \\
\hline high (DTPP) & 0.762 & (8.6) & 0.767 & (8.6) & 0.572 & (3.2) & 0.936 & (4.7) & 0.834 & (3.7) & 0.770 & (3.5) & 0.866 & (4.5) \\
\hline medium (DTP) & 0.420 & (13.0) & 0.421 & (12.9) & 0.456 & (6.2) & 0.441 & (6.1) & 0.309 & (4.3) & 0.420 & (5.7) & 0.504 & (6.9) \\
\hline$(1-U 6) S P$ & 52.392 & $(4.4)$ & 51.984 & (4.4) & 87.977 & (4.3) & 37.168 & (1.6) & 35.744 & (1.4) & 68.400 & (3.6) & 59.571 & (3.5) \\
\hline import share $(I M Q)$ & 0.261 & (5.1) & 0.265 & (5.2) & 0.278 & (2.3) & 0.086 & $(0.8)$ & 0.219 & (1.9) & 0.441 & (3.7) & 0.354 & (3.1) \\
\hline raw materials $(G)$ & -0.323 & $(-5.6)$ & -0.323 & $(-5.6)$ & -0.222 & $(-1.7)$ & -0.281 & $(-2.2)$ & -0.410 & $(-3.2)$ & -0.344 & $(-2.7)$ & -0.386 & $(-3.0)$ \\
\hline investment good $(I)$ & 0.025 & $(0.6)$ & 0.028 & $(0.6)$ & 0.011 & $(0.1)$ & -0.027 & $(0.3)$ & -0.073 & $(-0.7)$ & 0.114 & (1.2) & 0.085 & (0.9) \\
\hline Observations & \multicolumn{2}{|c|}{6625} & \multicolumn{2}{|c|}{6625} & \multirow{2}{*}{\multicolumn{2}{|c|}{1325}} & \multirow{2}{*}{\multicolumn{2}{|c|}{1325}} & \multirow{2}{*}{\multicolumn{2}{|c|}{1325}} & \multirow{2}{*}{\multicolumn{2}{|c|}{1325}} & \multirow{2}{*}{\multicolumn{2}{|c|}{1325}} \\
\hline - log Likelihood & 4356 & & 4075 & & & & & & & & & & & \\
\hline
\end{tabular}


The assumption of constant intercepts is only mildly rejected by a LR test $\left(\chi^{2}(4)=12, p=1.66 \%\right)$ given the sample size of 6625 . Yet the LR statistic will not have a $\chi^{2}$ distribution unless the individual-specific effect disappears from the true model, an assumption which is rejected by the data as we shall see below. The parameter values are very similar to those obtained in cross-section estimation, which also yields consistent estimates under the assumptions above. Apart from the sectoral dummy $I$ all variables have fairly well determined coefficients in the pooled probit estimation. Although the $t$-values reported are based on $M$-estimation theory, and are thus more robust to various kinds of misspecification than $t$-values based on maximum-likelihood estimation, they still may be asymptotically biased due to the lack of independence between observations of the same OPF in different periods.

The signs and significance of coefficients are by and large in agreement with those reported by Pohlmeier $(1989,1992)$. The relative firm size and the market size (captured here by $\ln Q B$ ) have a mildly significant positive impact on process innovation, as our model predicts. Yet demand expectations have a much more significantly positive impact. Through the variable $(1-U 6) S P$ concentration has a negative impact on process innovation. This is again in agreement with the Pohlmeier study which, allowing for endogeneity of the corresponding variable U3 (share of the three largest firms), found that concentration had a significantly negative impact on innovation. However, this is not consistent with our theoretical model, in which the coefficient on the variable $(1-U 6) S P$ is unambiguously positive, indicating that ceteris paribus a higher market concentration is associated with a lower innovation activity. A theoretical explanation for this discrepancy might be the invalidity of the Cournot assumption. Equation (2.13) shows that the impact of concentration on process innovation (via the mark-up factor) is not necessarily positive if the Cournot assumption $\eta_{i t}=0$ does not hold. An empirical explanation for this discrepancy could be the lack of correspondence between the dependent variable in the data and the dependent variable in the model. The latter is successfully installed process innovation, while the former could capture any type of innovative activity. Furthermore, our model assumes that a successfully installed process innovation is instantaneously cost reducing. This may well be at variance with reality. However, coping with this possibility would require a much more complicated intertemporal model.

Finally, the 'raw material' industries appear to innovate less than others over the period considered, although the difference is far from being significant in all periods. Joint Wald tests over all periods show all variables, except the investment good dummy and to a lesser degree relative firm size and market size, to have a strongly significant joint impact.

Pohlmeier interpreted the results from an information matrix test as evidence of a problem with neglected heterogeneity. Here we address this question using score tests. Joint generalized score tests against the omission of contemporaneous variables (the variables considered are $U 6, Q B, D T M M M, S U, S U 2, S U 8$, $W A G E$ and $C$, see Table 1 for details) show that one might consider including the 
dummies for negative demand expectations DTMMM and for small size of the OPF's enrolment relative to the firm SU2. More interesting are similar tests against the omission of leads and lags of included time varying regressors. Chamberlain's (1984) approach to the treatment of random individual effects correlated with the regressors consists in regressing these individual effects on the included regressors. The joint test for leads and lags reveals $S P+\ln Q B$ and $D T P$ as main candidates ( $\ln Q B$ and $D T P$ in the unrestricted model). Testing against lags only suggests the addition of $I M Q$, whereas testing for leads only points to $S P+\ln Q B$ and $D T P P$. Further joint generalized score tests against heteroscedasticity, misspecified functional form (RESET) and against non-normality (SNP; see, e.g. Gabler et al., 1993) show no particular problem.

4.1.2. Use of Chamberlain's minimum distance approach. Chamberlain's minimum distance approach to panel probit estimation has a distinct advantage over simple pooling of the observations in that it provides consistent estimates of the standard errors of the coefficients. Furthermore, it allows us to explicitly take account of both the presence of the stochastic idiosyncratic effect $v_{i}$ and autocorrelation in the $u_{i t}$ error terms of equation (4.1). It thus allows us to go some way towards meeting the constraints placed on the stochastic form of the model by equation (2.10). The method combines $M$-estimation (estimation of the reduced-form and its covariance matrix) and minimum-distance (imposition of restrictions implied by the structural model): see Chamberlain (1984) or Hsiao (1986) for details. When applying the approach, we start from the cross-section estimates of Table 2 and compare four different sets of restrictions on the model, according to whether or not period dummies are included and whether or not the variance of $v_{i}+u_{i t}$ is constrained to be equal across periods. From equation (2.10) we would expect both sets of restrictions to be rejected by the data. Figure 1 gives the corresponding $\chi^{2}$ tests based on the minimized criterion. Only the restriction on the intercepts is rejected, both unconditionally and conditional on the validity of the less restricted specification.

Table 3 gives the corresponding parameter estimates. These are fairly stable across columns and close to the pooled probit estimates, but the $t$-values reported are more reliable here. A remarkable feature of these results is that there is no important drop in estimated precision when taking account of unobserved heterogeneity or when allowing intercepts or variances to differ across periods.

\subsection{Heterogeneity Correlated with the Regressors}

In order to check whether neglected heterogeneity correlated with the included regressors might be a source for the observed misspecification, we specify $v_{i}=x_{i} \lambda+e_{i}$ with all regressors (with all their leads and lags) in $x_{i}$ except (I-U6)SP and $I M Q$, the leads and lags of which were not found to be missing, and of course the time invariant dummies $G$ and $I$, and apply the two stages of Chamberlain's approach. 


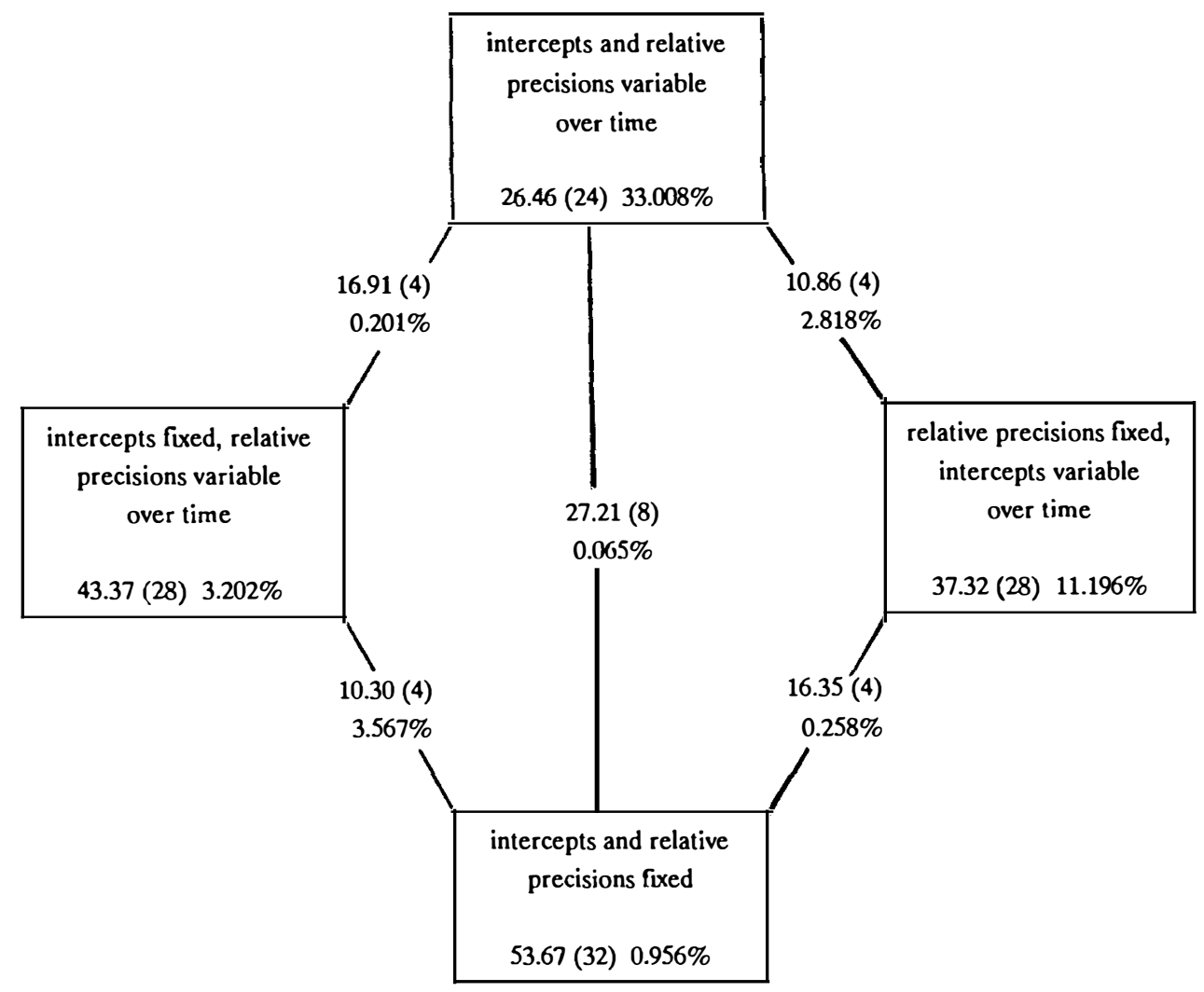

FIG. 1. Tests of restrictions in model with random effects uncorrelated with regressors.

Table 4 shows the results of the reduced form year to year probit estimation. A comparison with Table 2 shows that most coefficients are now very poorly determined. The underlined coefficients in the table are those one would expect not to be all too badly determined if the corresponding variable enters only $x_{i t k} \beta_{k}$ or if its impacts on $x_{i t k} \beta_{k}$ and $\lambda_{t k} x_{i t k}$ do not cancel each other. Coefficients that are well determined are underlined twice.

The model implies that the off-diagonal terms in each line of the table should be proportional across lines. At first glance, none of the variables is very encouraging in this respect. Yet concentrating on coefficients with a $t$-value above 1.3 (bold in the table), we can see that the lines corresponding to $S P+\ln Q B$ are not too bad.

Joint Wald tests show that the only variables which are jointly significant are the intercept, SPLNQB88, DTPP88, DTP84, DTP87, DTP88, G, (1-U6)SP and $I M Q$. Yet this provides no guide-line for excluding any variable. The MacAlvey-Zavoina $R$-square measure and the percentage of correct predictions for the 5 years separately and overall are given in Table 5 (values for the 
TABle 3. Panel Probit Estimates of Model with Random Effects Uncorrelated with Regressors

\begin{tabular}{|c|c|c|c|c|c|c|c|c|}
\hline Variable & Coefficient & $(t)$ & Coefficient & $(t)$ & Coefficient & $(t)$ & Coefficient & $(t)$ \\
\hline Intercept & -1.59 & $(-5.7)$ & -1.84 & $(-5.4)$ & & & & \\
\hline Intercept 1984 & & & & & -1.54 & $(-5.5)$ & -1.76 & $(-5.2)$ \\
\hline Intercept 1985 & & & & & -1.61 & $(-5.7)$ & -1.85 & $(-5.4)$ \\
\hline Intercept 1986 & & & & & -1.45 & $(-5.1)$ & -1.62 & $(-4.7)$ \\
\hline Intercept 1987 & & & & & -1.55 & $(-5.4)$ & -1.78 & $(-5.2)$ \\
\hline Intercept 1988 & & & & & -1.52 & $(-5.3)$ & -1.76 & $(-5.1)$ \\
\hline$S P+\ln Q B$ & 0.12 & (4.3) & 0.13 & (3.9) & 0.11 & $(4.0)$ & 0.12 & (3.7) \\
\hline \multicolumn{9}{|l|}{ Demand expectation } \\
\hline high (DTPP) & 0.74 & $(6.8)$ & 0.90 & $(6.3)$ & 0.73 & (6.7) & 0.88 & (6.2) \\
\hline medium (DTP) & 0.42 & (10.4) & 0.51 & (8.8) & 0.43 & (10.3) & 0.51 & (8.5) \\
\hline$(1-U 6) S P$ & 63.11 & $(5.2)$ & 71.36 & $(5.0)$ & 61.75 & (5.0) & 69.05 & (4.9) \\
\hline import share (IMQ) & 0.24 & (3.3) & 0.34 & (3.9) & 0.25 & (3.5) & 0.35 & (4.0) \\
\hline raw materials $(G)$ & -0.34 & $(-4.3)$ & -0.39 & $(-4.0)$ & -0.34 & $(-4.3)$ & -0.38 & $(-3.9)$ \\
\hline investment good $(I)$ & 0.00 & $(0.0)$ & 0.06 & $(0.7)$ & 0.01 & $(0.1)$ & 0.06 & $(0.8)$ \\
\hline$\alpha_{1984}{ }^{1}$ & & & 0.766 & $(-2.4)$ & & & 0.779 & $(-2.1)$ \\
\hline$\alpha_{1985}$ & & & 0.701 & $(-3.4)$ & & & 0.742 & $(-2.7)$ \\
\hline$\alpha_{1986}$ & & & 0.673 & $(-3.4)$ & & & 0.643 & $(-3.7)$ \\
\hline$\alpha_{1987}$ & & & 0.914 & $(-0.8)$ & & & 0.939 & $(-0.6)$ \\
\hline$\alpha_{1988}$ & & & 1.000 & & & & 1.000 & \\
\hline$\chi^{2}$ & 53.67 & & 43.37 & & 37.32 & & 26.46 & \\
\hline Degrees of freedom & & & 28 & & 28 & & 24 & \\
\hline Empirical significance & $0.956 \%$ & & $3.20 \%$ & & $11.20 \%$ & & $33.01 \%$ & \\
\hline
\end{tabular}

\footnotetext{
${ }^{1} t$-values for $H^{0}: \alpha=1$.
} 
TABLE 4. Reduced Form Cross-section Probit Estimates for Model with Random Effects Correlated with the Regressors

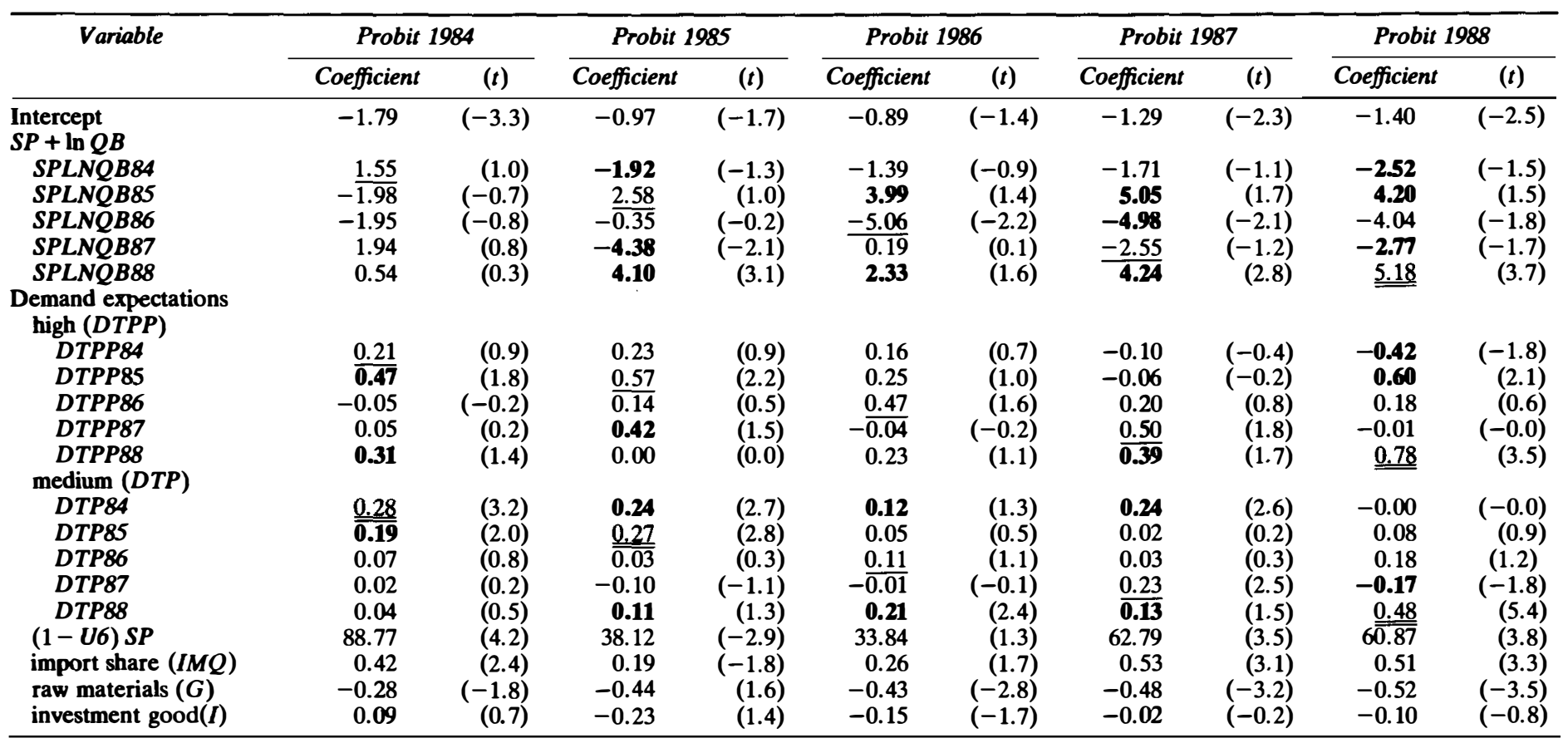


TABLE 5 .

\begin{tabular}{lcccccc}
\hline & 1984 & 1985 & 1986 & 1987 & 1988 & Overall \\
\hline $\begin{array}{l}\text { MacAlvey-Zavoina } \\
R \text {-square (\%) }\end{array}$ & 16.39 & 13.27 & $\mathbf{1 0 . 4 8}$ & 18.46 & $\mathbf{1 9 . 8 7}$ & $\mathbf{1 6 . 1 0}$ \\
Correct predictions(\%) & $(16.00)$ & $(\mathbf{1 3 . 9 2})$ & $(9.36)$ & $(\mathbf{2 1 . 3 3 )}$ & $(17.59)$ & $(\mathbf{1 6 . 0 7 )}$ \\
& $\mathbf{6 2 . 0 4}$ & $\mathbf{6 2 . 6 4}$ & $\mathbf{6 2 . 7 2}$ & $\mathbf{6 3 . 6 2}$ & $\mathbf{6 4 . 0 8}$ & $\mathbf{6 3 . 0 2}$ \\
& $(61.58)$ & $(61.58)$ & $(61.21)$ & $(62.64)$ & $(63.32)$ & $(62.07)$ \\
\hline
\end{tabular}

unrestricted model in parentheses). The restricted model dominates the unrestricted model on both criteria, although the constraint is rejected by the data.

The joint generalized score tests against the omission of contemporaneous variables show that once again $S U 2$ is a candidate for inclusion. Yet this is not confirmed by the test from the unrestricted model. Similarly, a test against missing of all leads and lags of the variables listed in Subsection 4.1.1 points to $Q B$ when using the restricted model but this is not confirmed by the test using the unrestricted model. Tests against the omission of leads and lags of included time varying regressors only point to the better specification of the unrestricted model, from the statistical point of view, as do tests against heteroscedasticity. Again the RESET and SNP tests are passed easily, although surprisingly the RESET test is more doubtful for the unrestricted model.

The (second stage) tests reported in Fig. 2 indicate a clear rejection of the overall specification. (Imposing constant variances or constant intercepts leads to no rejection conditional on a correct overall specification, although imposing both appears doubtful.) However, the Wald tests of Table 6 clearly

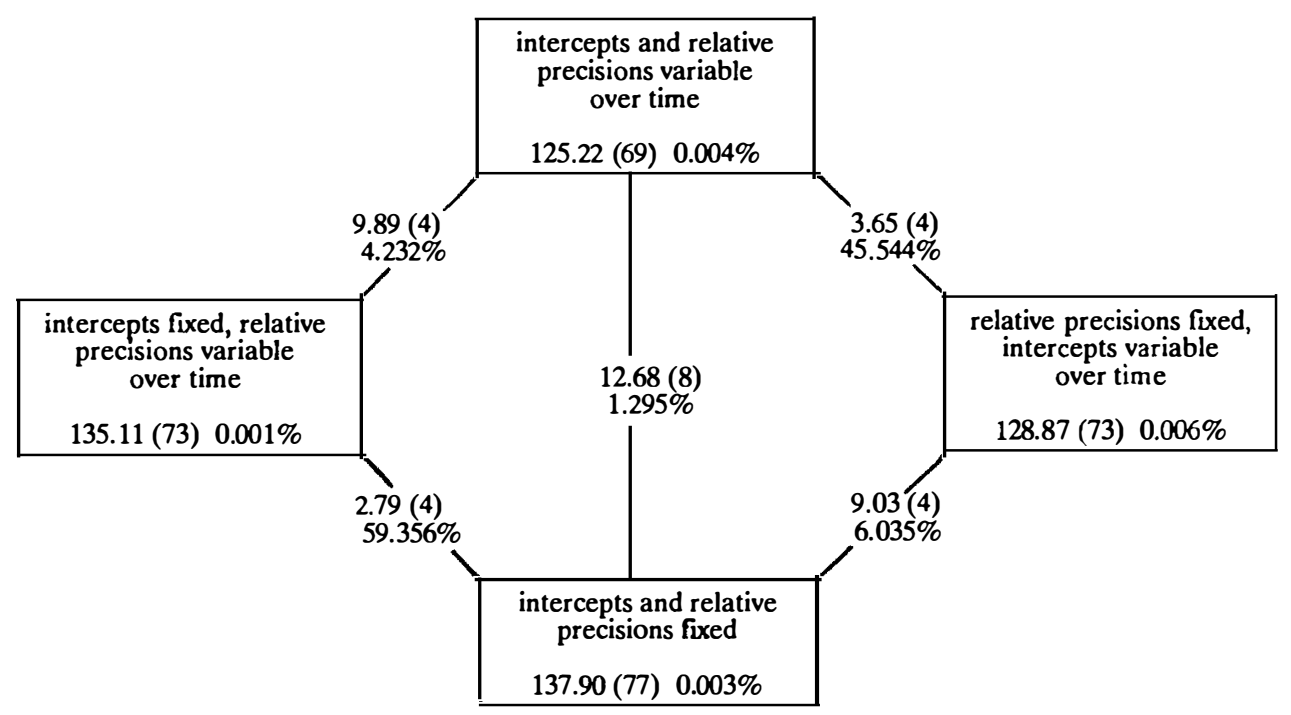

FIG. 2. Tests of restrictions in model with random effects correlated with regressors. 
TABLE 6. Wald Tests for Panel Probit Models (Columns Correspond to those of Tables 3 and 7)

\begin{tabular}{|c|c|c|c|c|}
\hline$\chi^{2}(15)$ (significance \%) & $161(0.00000)$ & $101(0.00000)$ & $150(0.00000)$ & $93(0.00000)$ \\
\hline \multicolumn{5}{|c|}{ No correlation between random effect and specific regressors $\chi^{2}(5)$ (significance $\%$ ) } \\
\hline $\begin{array}{l}S P+\ln Q B \\
D T P P \\
D T P\end{array}$ & $\begin{array}{l}35.8(0.0001) \\
37.7(0.0000) \\
70.7(0.0000)\end{array}$ & $\begin{array}{l}31.8(0.0007) \\
31.6(0.0007) \\
54.7(0.0000)\end{array}$ & $\begin{array}{l}33.9(0.0003) \\
38.5(0.0000) \\
64.4(0.0000)\end{array}$ & $\begin{array}{l}30.6(0.0011) \\
31.7(0.0007) \\
48.2(0.0000)\end{array}$ \\
\hline
\end{tabular}

reject the 'uncorrelated random effects' specification as well: $\lambda=0$ is clearly rejected for all variables.

In discussing the results of Table 7 we concentrate on a comparison of its fourth column with the fourth column of Table 3 . The only model parameters that remain significant are the parameters of variables that have not been included in the heterogeneity term. This suggests that the main problem affecting this specification is the high autocorrelation of the included regressors. In this respect it might be a good idea to revert to Mundlak's original proposal of explaining the individual effects by the time means of the exogenous regressors.

Another possible explanation for the rejection of the correlated random effects specification, besides possible structural instability as well as various other sources of misspecification like measurement errors, etc., lies in the failure of strict exogeneity of the variables $S P+\ln Q B, D T P P$, and $D T P$ conditional on the random effect.

\section{CONCLUSIONS}

In this paper we reconsidered static models of the process innovation behaviour of West German exporting firms in the light of panel data. Our starting point was the model estimated by Pohlmeier $(1989,1992)$, with a few departures due to differences in the data sets used. Our five cross-section estimates reproduce the qualitative properties of his: all significant coefficients retain the signs and magnitudes they had in his cross-section estimates. However, cross-section or pooling estimators are inconsistent in the presence of neglected heterogeneity when the latter is correlated with the regressors or produces heteroscedasticity.

Our main tool of investigation here is Chamberlain's approach to modelling random effects. We first specify normally distributed random effects uncorrelated with the regressors and examine the validity of two restrictions: constant intercepts and constant reduced form variances. Neither the unrestricted model nor the restriction of equal variances are rejected, but the restriction of equal intercepts is. This could be interpreted as encouraging the investigation of further time-varying coefficients, as suggested by the exposition of our theoretical model. Normality, homoscedasticity and the adequacy of the functional form all pass joint generalized score tests. However, the leads and lags of three of the regressors appear as missing variables. Since correlation between the latent 
F. LAISNEY et al.

TABLE 7. Panel Probit Estimates of Model with Random Effects Correlated with Regressors

\begin{tabular}{|c|c|c|c|c|c|c|c|c|}
\hline Variable & Coefficients & $(t)$ & Coefficients & $(t)$ & Coefficients & $(t)$ & Coefficients & $(t)$ \\
\hline $\begin{array}{l}\text { Intercept } \\
\text { Intercept } 1984 \\
\text { Intercept } 1985 \\
\text { Intercept } 1986 \\
\text { Intercept } 1987 \\
\text { Intercept } 1988\end{array}$ & -1.45 & $(-4.2)$ & -1.56 & $(-4.0)$ & $\begin{array}{l}-1.52 \\
-1.29 \\
-1.40 \\
-1.52 \\
-1.42\end{array}$ & $\begin{array}{l}(-3.8) \\
(-3.2) \\
(-3.8) \\
(-4.2) \\
(-3.9)\end{array}$ & $\begin{array}{l}-1.65 \\
-1.33 \\
-1.46 \\
-1.61 \\
-1.53\end{array}$ & $\begin{array}{l}(-3.5) \\
(-3.0) \\
(-3.6) \\
(-4.0) \\
(-3.8)\end{array}$ \\
\hline $\begin{array}{l}S P+\ln Q B \\
D T P P \\
D T P \\
(1-U 6) S P \\
I M Q\end{array}$ & $\begin{array}{r}0.04 \\
-0.05 \\
0.05 \\
59.60 \\
0.38\end{array}$ & $\begin{array}{r}(1.0) \\
(-1.2) \\
(1.4) \\
(5.2) \\
(3.7)\end{array}$ & $\begin{array}{r}0.04 \\
-0.05 \\
0.01 \\
63.53 \\
0.44\end{array}$ & $\begin{array}{r}(1.0) \\
(-1.3) \\
(1.5) \\
(5.1) \\
(3.8)\end{array}$ & $\begin{array}{r}-0.02 \\
-0.00 \\
0.03 \\
58.19 \\
0.37\end{array}$ & $\begin{array}{r}(-0.5) \\
(-0.0) \\
(1.0) \\
(5.1) \\
(3.6)\end{array}$ & $\begin{array}{r}-0.02 \\
-0.04 \\
0.05 \\
61.85 \\
0.41\end{array}$ & $\begin{array}{r}(-0.3) \\
(-0.3) \\
(1.0) \\
(5.0) \\
(3.7)\end{array}$ \\
\hline $\begin{array}{l}G \\
I\end{array}$ & $\begin{array}{l}-0.43 \\
-0.08\end{array}$ & $\begin{array}{l}(-4.5) \\
(-1.0)\end{array}$ & $\begin{array}{l}-0.47 \\
-0.08\end{array}$ & $\begin{array}{l}(-4.4) \\
(-0.9)\end{array}$ & $\begin{array}{l}-0.43 \\
-0.09\end{array}$ & $\begin{array}{l}(-4.5) \\
(-1.1)\end{array}$ & $\begin{array}{l}-0.48 \\
-0.03\end{array}$ & $\begin{array}{l}(-4.3) \\
(-1.0)\end{array}$ \\
\hline $\begin{array}{l}\text { SPLNQB } 84 \\
\text { DTPP } 84 \\
\text { DTP } 84\end{array}$ & $\begin{array}{r}-0.93 \\
0.07 \\
0.14\end{array}$ & $\begin{array}{r}(-1.0) \\
(0.4) \\
(2.5)\end{array}$ & $\begin{array}{r}-1.13 \\
0.01 \\
0.15\end{array}$ & $\begin{array}{r}(-1.1) \\
(0.1) \\
(2.3)\end{array}$ & $\begin{array}{r}-0.98 \\
0.07 \\
0.14\end{array}$ & $\begin{array}{r}(-1.0) \\
(0.4) \\
(2.4)\end{array}$ & $\begin{array}{r}-1.27 \\
-0.03 \\
0.14\end{array}$ & $\begin{array}{r}(-1.2) \\
(-0.0) \\
(2.3)\end{array}$ \\
\hline $\begin{array}{l}\text { SPLNOB } 85 \\
\text { DTPP } 85 \\
\text { DTP } 85\end{array}$ & $\begin{array}{l}2.37 \\
0.32 \\
0.14\end{array}$ & $\begin{array}{l}(1.4) \\
(1.8) \\
(2.3)\end{array}$ & $\begin{array}{l}2.56 \\
0.37 \\
0.15\end{array}$ & $\begin{array}{l}(1.3) \\
(1.9) \\
(2.2)\end{array}$ & $\begin{array}{l}2.50 \\
0.34 \\
0.13\end{array}$ & $\begin{array}{l}(1.4) \\
(1.9) \\
(2.2)\end{array}$ & $\begin{array}{l}2.84 \\
0.37 \\
0.13\end{array}$ & $\begin{array}{l}(1.5) \\
(1.9) \\
(2.1)\end{array}$ \\
\hline $\begin{array}{l}\text { SPLNOB } 86 \\
\text { DTPP } 86 \\
\text { DTP } 86\end{array}$ & $\begin{array}{r}-3.57 \\
0.14 \\
0.05\end{array}$ & $\begin{array}{r}(-2.4) \\
(0.7) \\
(0.8)\end{array}$ & $\begin{array}{r}-3.70 \\
0.11 \\
0.05\end{array}$ & $\begin{array}{r}(-2.3) \\
(0.5) \\
(0.7)\end{array}$ & $\begin{array}{r}-3.50 \\
0.17 \\
0.07\end{array}$ & $\begin{array}{r}(-2.4) \\
(0.8) \\
(1.1)\end{array}$ & $\begin{array}{r}-3.54 \\
0.17 \\
0.06\end{array}$ & $\begin{array}{r}(-2.2) \\
(0.6) \\
(0.9)\end{array}$ \\
\hline $\begin{array}{l}\text { SPLNQB } 87 \\
\text { DTPP } 87 \\
\text { DTP } 87\end{array}$ & $\begin{array}{r}-1.57 \\
0.10 \\
-0.02\end{array}$ & $\begin{array}{l}(-1.1) \\
-(0.6) \\
(-0.3)\end{array}$ & $\begin{array}{r}-1.86 \\
0.14 \\
-0.01\end{array}$ & $\begin{array}{r}(-1.2) \\
(0.8) \\
(-0.2)\end{array}$ & $\begin{array}{r}-1.42 \\
0.08 \\
-0.03\end{array}$ & $\begin{array}{r}(-1.2) \\
(0.5) \\
(-0.4)\end{array}$ & $\begin{array}{r}-2.14 \\
0.15 \\
-0.10\end{array}$ & $\begin{array}{r}(-1.4) \\
(0.8) \\
(-0.3)\end{array}$ \\
\hline $\begin{array}{l}\text { SPLNQB } 88 \\
D T P P 88 \\
D T P 88\end{array}$ & $\begin{array}{l}3.77 \\
0.39 \\
0.23\end{array}$ & $\begin{array}{l}(3.9) \\
(2.8) \\
(4.1)\end{array}$ & $\begin{array}{l}4.21 \\
0.43 \\
0.27\end{array}$ & $\begin{array}{l}(3.8) \\
(2.7) \\
(4.2)\end{array}$ & $\begin{array}{l}3.77 \\
0.39 \\
0.22\end{array}$ & $\begin{array}{l}(3.9) \\
(2.8) \\
(3.8)\end{array}$ & $\begin{array}{l}4.22 \\
0.42 \\
0.29\end{array}$ & $\begin{array}{l}(3.8) \\
(2.7) \\
(3.8)\end{array}$ \\
\hline $\begin{array}{l}\alpha_{1984} \\
\alpha_{1985} \\
\alpha_{1986} \\
\alpha_{1987} \\
\alpha_{1988}\end{array}$ & $\begin{array}{l}1.00 \\
1.00 \\
1.00 \\
1.00 \\
1.00\end{array}$ & & $\begin{array}{l}0.88 \\
0.89 \\
0.81 \\
0.93 \\
1.00\end{array}$ & $\begin{array}{l}(-1.1) \\
(-1.2) \\
(-2.0) \\
(-0.7)\end{array}$ & $\begin{array}{l}1.00 \\
1.00 \\
1.00 \\
1.00 \\
1.00\end{array}$ & & $\begin{array}{l}0.86 \\
0.90 \\
0.79 \\
0.94 \\
1.00\end{array}$ & $\begin{array}{l}(-1.3) \\
(-0.9) \\
(-2.1) \\
(-0.5)\end{array}$ \\
\hline $\begin{array}{l}\chi^{2} \\
\text { Degrees of free } \\
\text { Empirical signif }\end{array}$ & \multicolumn{2}{|c|}{$\begin{array}{lc} & 137.9 \\
\text { dom } & 77 \\
\text { ficance } & 0.0025 \%\end{array}$} & \multicolumn{2}{|c|}{$\begin{array}{c}135.1 \\
73 \\
0.0014 \%\end{array}$} & \multicolumn{2}{|c|}{$\begin{array}{c}128.9 \\
73 \\
0.0060 \%\end{array}$} & \multicolumn{2}{|c|}{$\begin{array}{c}125.2 \\
69 \\
0.0041 \%\end{array}$} \\
\hline
\end{tabular}

heterogeneity and the regressors may cause inconsistency, we proceed with estimation allowing for such correlation and include leads and lags of the regressors in the first stage reduced form probit estimation. Now the overall specification is rejected while the diagnostic tests still lead to the same conclusions, and the absence of correlation between random effects and regressors is strongly rejected. While acknowledging the possibility that lack of strict exogeneity of the regressors or their high autocorrelation may be at work here, 
we think that the relatively good performance of the reduced form suggests that relaxing the restrictions on the structural form, allowing for varying coefficients or some sort of dynamics, may lead to good results.

Thus we see three distinct directions for further work on this topic. The first one is more or less purely econometric and consists of investigating in detail the shortcomings listed above and their possible impact on our conclusions. The second consists of estimating further specifications with varying coefficients. The third one is more ambitious and would consist of specifying truly dynamic models of innovation behaviour which could be estimated with the data at hand, possibly using the estimators presented by Lechner (1991).

\section{ACKNOWLEDGEMENTS}

Support from the Deutsche Forschungsgemeinschaft and from the Centre for European Economic Research (Zentrum für Europäische Wirtschaftsforschung-ZEW) is gratefully acknowledged. We also wish to thank the Ifo-Institute, and especially Gernot Nerb and Lothar Scholz, for fruitful collaboration, and our colleagues in Mannheim as well as Manuel Arellano and Viktor Steiner. The critical comments of two anonymous referees are also gratefully acknowledged. The usual disclaimer applies.

\section{REFERENCES}

Breshnahan, T. M. (1989). 'Empirical Studies of Industries with Market Power', in R. Schmalensee and Willig R. D. (eds), Handbook of Industrial Organization, Vol. II, 1011-57. NorthHolland, Amsterdam.

Bronstein, I. N. and Semendjajev, K. A. (1983). Taschenbuch der Mathematik, 21st edn. Teubner, Leipzig.

Chamberlain, G. (1984). 'Panel Data', in Z. Griliches and M. D. Intriligator (eds), Handbook of Econometrics, Vol. II. Elsevier, New York.

Gabler, S., Laisney, F. and Lechner, M. (1993). 'Semi-Nonparametric Maximum Likelihood Estimation of Binary Choice Models with an Application to Labour Force Participation', Journal of Business and Economic Statistics, 11, 61-81.

GrILICHES, Z. (1979). 'Issues in Assessing the Contribution of Research and Development to Productivity Growth', Bell Journal of Economics, 10, 92-116.

Hall, B. H. and HaYashi, F. (1989). 'Research and Development as an Investment', Working Paper 89-108. University of California, Berkeley.

Hotz, V. J., Kydland, F. E. and Sedlacek, G. L. (1988). 'Intertemporal Preferences and Labour Supply', Econometrica, 56, 335-60.

Hsiao, C. (1986). The Analysis of Panel Data. Cambridge University Press, Cambridge.

Kamien, M. I. and SchwarTZ, N. L. (1969). 'Induced Factor Augmenting Technical Progress from a Microeconomic Viewpoint', Econometrica, 37, 668-84.

LeCHNER, M. (1991). 'Estimation of Dynamic Limited Dependent Variable Models on Panel Data: Theory and Monte Carlo Evidence', in Beiträge zur Angewandten Wirtschaftsforschung, 460-91, Universität Mannheim.

- (1992). 'Some Specification Tests for Static Limited Dependent Variable Models Estimated on Panel Data', Beiträge zur Angewandten Wirtschaftsforschung, 474-92. Universität Mannheim.

LeE, L. F. and PORTER, R. H. (1984). 'Switching Regression Models with Imperfect Sample Separation Information-with an Application on Cartel Stability', Econometrica, 52, 391-18.

LinK, A. N. (1980). 'Firm Size and Efficient Entrepreneurial Activity: A Reformulation of the Schumpeter Hypothesis', Journal of Political Economy, 88, 771-82.

MaIREsse, J. and Griliches, Z. (1990). 'Heterogeneity in Panel Data: Are There Stable Production Functions?', in Essays in Honor of Edmond Malinvaud, Vol. 3: Empirical Economics, 192-231. MIT Press, Cambridge, MA. 
OpPenländer, K. H. and Poser, G. (eds) (1989). Handbuch der Ifo-Umfragen. Duncker \& Humblot, Berlin.

Pohlmeier, W. (1989). Simultane Probit- und Tobitmodelle: Theorie und Anwendung auf Fragen der Innovationsökonomik. Springer Verlag, Heidelberg.

- (1992). 'On the Simultaneity of Innovation and Market Structure', Empirical Economics, 17, 253-272.

PORTER, R. H. (1983). 'A study of cartel stability: The Joint Executive Committee, 1889-1886', Bell Journal of Economics, 14, 301-14.

Robinson, P. M. (1982). 'On the Asymptotic Properties of Estimators of Models Containing Limited Dependent Variables', Econometrica, 50, 27-41.

RonNing, G. (1990). 'The Informational Content of Responses from Business Surveys', in J. P. Florens, M. Ivaldi, J. J. Laffont and F. Laisney (eds), Microeconometrics: Surveys and Applications, 123-44. Basil Blackwell, Oxford.

SHAPIRO, C. (1989). 'Theories of Oligopoly Behaviour', in R. Schmalensee and R. D. Willig (eds), Handbook of Industrial Organization, Vol. I, 329-414. North-Holland, Amsterdam. 